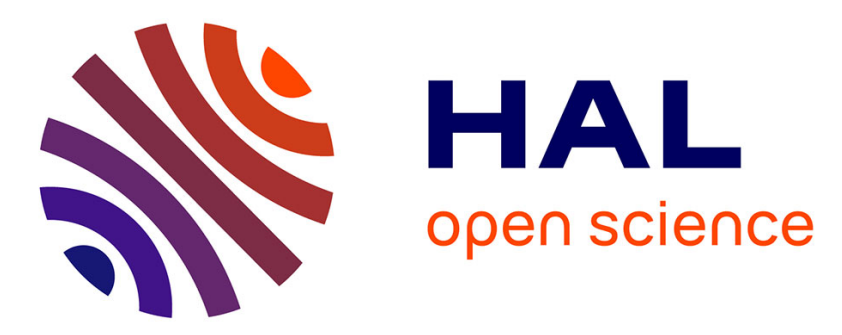

\title{
Novel Sext-Band Band-Pass Filter with Non-Coupled Structure Based on Multi-Shorted-Stub Resonators
}

\author{
Yi Wu, Erwan Fourn, Philippe Besnier
}

\section{To cite this version:}

Yi Wu, Erwan Fourn, Philippe Besnier. Novel Sext-Band Band-Pass Filter with Non-Coupled Structure Based on Multi-Shorted-Stub Resonators. 2020 Asia-Pacific Microwave Conference (APMC2020),

Dec 2020, Hong Kong, China. hal-03066340

\section{HAL Id: hal-03066340 \\ https://hal.science/hal-03066340}

Submitted on 11 Jan 2021

HAL is a multi-disciplinary open access archive for the deposit and dissemination of scientific research documents, whether they are published or not. The documents may come from teaching and research institutions in France or abroad, or from public or private research centers.
L'archive ouverte pluridisciplinaire HAL, est destinée au dépôt et à la diffusion de documents scientifiques de niveau recherche, publiés ou non, émanant des établissements d'enseignement et de recherche français ou étrangers, des laboratoires publics ou privés. 


\section{Novel Sext-Band Band-Pass Filter with Non-Coupled Structure Based on Multi-Shorted-Stub Resonators}

\author{
$\mathrm{Yi} \mathrm{Wu}$ \\ Univ Rennes, INSA Rennes, IETR, UMR CNRS 6164 \\ Rennes, France \\ Yi.Wu@insa-rennes.fr
}

Philippe Besnier

Univ Rennes, INSA Rennes, IETR, UMR CNRS 6164

Rennes, France

Philippe.Besnier@insa-rennes.fr

\author{
Erwan Fourn \\ Univ Rennes, INSA Rennes, IETR, UMR CNRS 6164 \\ Rennes, France \\ Erwan.Fourn@insa-rennes.fr
}

\begin{abstract}
In this paper, we present a simple way to design sextband band-pass filter based on multi-shorted-stub resonators. Each sext-band resonator consists in the parallel association of five stepped-impedance resonators in a non-coupled structure and allows the control of transmission zeros and bandwidths. A second-order sext-band band-pass filter is synthesized and realized in microstrip technology, the final circuit successfully integrating five stubs per resonators into a single planar circuit. Compared with coupled structures, the solution proposed here can achieve good in-band responses, band-to-band isolation with a simple design procedure. It also needs less optimization. All of these merits make this filter an attractive solution for multi-band wireless communication systems.
\end{abstract}

Index Terms-Sext-band band-pass filter, shorted-stub resonators, Chebyshev filter, star-like topology.

\section{INTRODUCTION}

Multi-band band-pass filters (BPFs) with high performance are more and more needed in modern wireless communication systems. Nevertheless, their design is highly challenging when the number of bands increases. This paper focuses on the case of sext-band BPF for which only few papers were already published [1]- [4]. In [1], a sext-band BPF was constructed by using various quarter-wavelength stepped-impedance resonators (SIRs). By controlling the combinations of SIRs with different impedance ratios and electrical length ratios, several resonant frequencies were achieved to design the filter. In [2], authors developed a sext-band BPF by using semi-lumped resonators, which consist of two identical microstrip lines and a chip inductor at the center. Compared with half-wavelength resonators, these semi-lumped resonators are compact and allow a better control of the harmonic frequencies. In [3], a single multi-mode resonator was proposed to design a sextband BPF with wide upper stop-band and high band-to-band isolation. Moreover, thanks to these multi-mode resonators, reflection zeros (RZ) and transmission zeros (TZ) can be controlled by adjusting the electrical lengths of two openended stubs. In [4], the use of SIR cascading stages, leads to a miniaturized sext-band BPF. However, the band-to-band isolation and pass-band ripple level are not satisfying. All these sext-band BPFs are synthesized by coupled structures. However, multi-band (BPFs) based on coupled structures have some drawbacks. It is therefore difficult to obtain an adequate adjustment of the filter responses with most design methods. As a result, one may rarely meet all the design requirements for all pass-bands simultaneously. Such multi-band BPF also suffer from in-band or band-to-band poor performance and numerous optimization steps are often needed. Most of these drawbacks are also true for the rare published works on BPF with seven or more bands [5]-[8].

In this paper, we propose a non-coupled structure to design sext-band BPF based on Multi-Shorted-Stub Resonators (MSSR) implemented in a star-like topology. A simple but efficient method is then proposed to design the sext-band filter. Measurements validate the proposed theory and designh techniques. Good simulation results and show that this MSSR topology is a good candidate for synthesizing sext-band BPFs.

\section{ThEORY OF NON-COUPLED MULTI-ShORTED-STUB RESONATORS}

The proposed MSSR is constructed by combining several SIRs. As shown in Fig.1, such a resonator is composed of five short-ended branches on a star-like implementation. For simplicity, we assume that the electrical length of each part of the branch $i(i \in[1 ; 5])$ of the MSSR equals to $\lambda / 4$ (or $\theta_{i}=\pi / 2$ in Fig. 1) at its resonant frequency $f_{z i}$ which will, at the end, correspond to a transmission zero. So the total input admittance can be written as:

$$
Y_{t o t}=\sum_{i=1}^{5} Y_{i}=j \sum_{i=1}^{5} \frac{Z_{i 2} \tan ^{2}\left(\frac{f}{f_{z i}} \frac{\pi}{2}\right)-Z_{i 1}}{Z_{i 1}\left(Z_{i 1}+Z_{i 2}\right) \tan \left(\frac{f}{f_{z i}} \frac{\pi}{2}\right)}
$$

where $Y_{\text {tot }}$ denotes the total input characteristic admittance of the sext-band resonator, $f$ is the frequency and $Z_{i 1}$ and $Z_{i 2}$ 


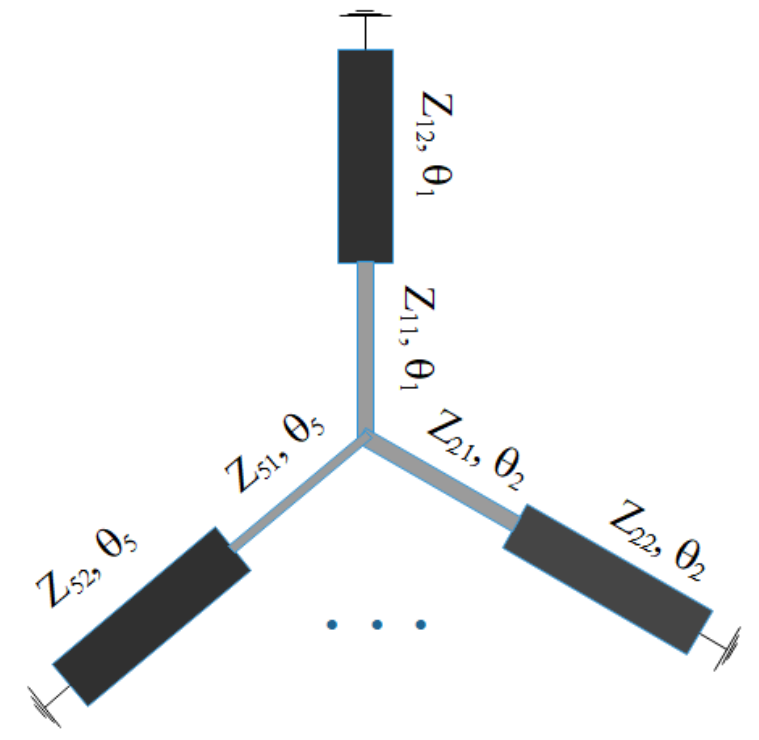

Fig. 1. Proposed Multi-Shorted-Stub Resonators (MSSR) topology.

are the characteristic impedance of the first and the second parts of the $i^{\text {th }}$ short-ended stub $(i \in[1 ; 5])$. It is easy to show that the $\mathrm{TZ}$ are obtained when $f=f_{z i}$. In this condition, the input admittance goes to infinity and each transmission zero $f_{z i}$ determines the length of the associated branch $i$. So, firstly, five TZ are produced, one per SIR. In fact, one can also take into account two additional TZ: one at the origin $\left(f_{z 0}=0 \mathrm{~Hz}\right)$ and another, called $f_{z 6}$, which is the first harmonic of $f_{z 1}$. Of course, these two additional TZ cannot be fixed independently. One reflection zero can be obtained between each TZ leading to a total of six pass-bands. These RZ appear when $Y_{\text {tot }}=0$. One should notice that this equation is non-linear as the one associated to the slope parameter that can be easily deduced from (1). So to simplify the filter conception, an optimization was made to determine the impedances $Z_{i 1}$ and $Z_{i 2}$, knowing that the firsts need to be higher than possible and the second relatively low to obtain narrow rejected bands between each pass-band frequency.

An example of such a sext-band resonator was designed with the following input parameters:

- Transmission zeros: $f_{z 1}=1.8 \mathrm{GHz}, f_{z 2}=2.1 \mathrm{GHz}$, $f_{z 3}=2.4 \mathrm{GHz}, f_{z 4}=2.7 \mathrm{GHz}, f_{z 5}=3.0 \mathrm{GHz}$ and so $f_{z 6}=2 f_{z 1}=3.6 \mathrm{GHz}$

- Reflection zeros: $f_{01}=1.650 \mathrm{GHz}, f_{02}=1.935 \mathrm{GHz}$, $f_{03}=2.245 \mathrm{GHz}, f_{04}=2.520 \mathrm{GHz}, f_{05}=2.815 \mathrm{GHz}$, $f_{06}=3.115 \mathrm{GHz}$.

Its frequency response is presented in Fig.2.It was obtained from (1) after solving for $Z_{i 1}$ and $Z_{i 2}$ and exhibits the required performance of a sext-band filter with such narrow rejection bands.

An $N$-order sext-band band-pass filter could then be designed using $N$ MSSR and J-inverters as presented schematically in Fig.3.

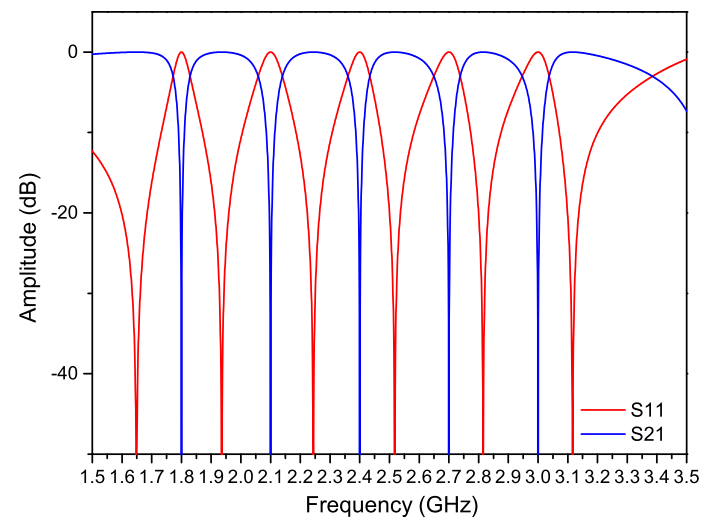

Fig. 2. Single resonator's $S$ parameters with $Z_{11}=138 \Omega, Z_{12}=23.1 \Omega$, $Z_{21}=137.8 \Omega, Z_{22}=30 \Omega, Z_{31}=136 \Omega, Z_{32}=22 \Omega, Z_{41}=24 \Omega$, $Z_{42}=23 \Omega, Z_{51}=138 \Omega, Z_{52}=22 \Omega$

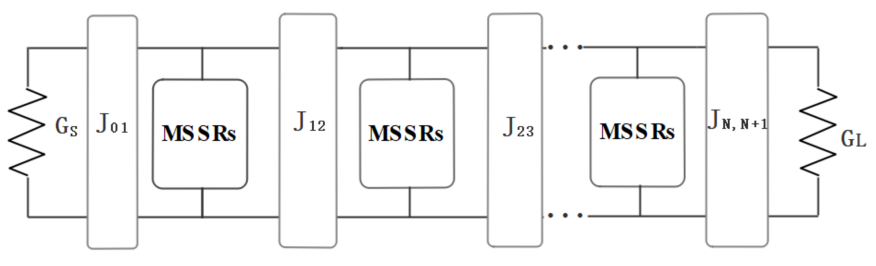

Fig. 3. The schematic of a $N$-order multi-band BPF based on the proposed MSSR.

\section{DESIGN AND CHARACTERIZATION OF A SECOND-ORDER SEXT-BAND FILTER}

As an example, a second-order sext-band band-pass filter has been designed. The two sext-band resonators used here are identical and are based on the one sizing in the previous section. The admittance value of the inverters are $J_{01}=0.0125 S$ and $J_{12}=0.00862 S$ respectively. The ideal frequency responses are presented in Fig.4 and again fulfill the initial requirements. All the pass-bands return losses are better than $-20 \mathrm{~dB}$ and the bandwidths are equal to $56 \mathrm{MHz}$, $59 \mathrm{MHz}, 55 \mathrm{MHz}, 50 \mathrm{MHz}, 48 \mathrm{MHz}, 47 \mathrm{MHz}$ respectively.

This filter was then implemented in microstrip technology. It was fabricated on Rogers RO4003 substrate of height $h=$ $0.508 \mathrm{~mm}$, relative permittivity $\varepsilon_{r}=3.55$ and loss tangent $\tan \delta=0.0027$. The sext-band band-pass filter was designed using ADS 2017 from Keysight Technologies $\odot$. Mitigation of cross-coupling was realized by appropriate arrangement of all the resonators. A photograph of the fabricated filter is shown in Fig.5. For each sext-band resonators, the dimensions of the filter are the following (all in millimetres): $L_{s}=20.00, W_{s}=$ $1.13, L_{01}=18.55, W_{01}=0.47, L_{02}=19.00, W_{02}=0.18$, $L_{11}=26.64, W_{11}=0.10, L_{12}=23.81, W_{12}=3.35, L_{21}=$ $22.83, W_{21}=0.10, L_{22}=20.73, W_{22}=2.38, L_{31}=0.11$, $W_{31}=19.96, L_{32}=17.60, W_{32}=3.55, L_{41}=17.73$, $W_{41}=0.12, L_{42}=15.60, W_{42}=3.36, L_{51}=15.98, W_{51}=$ $0.10, L_{52}=13.8, W_{52}=3.55$. 


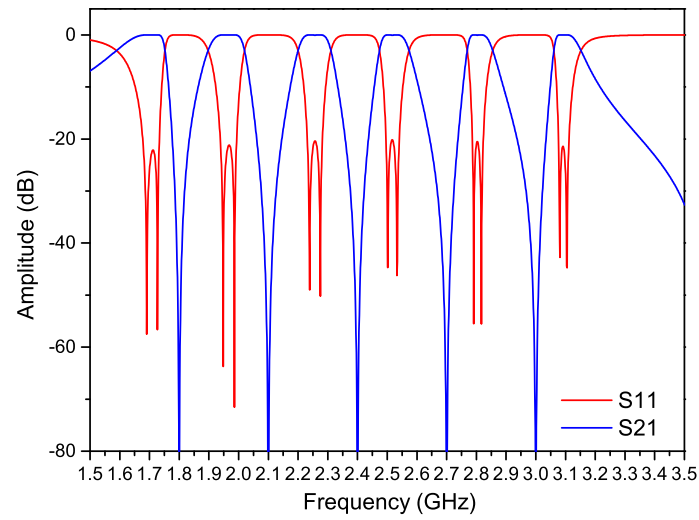

Fig. 4. S-parameters of the proposed sext-band BPF.

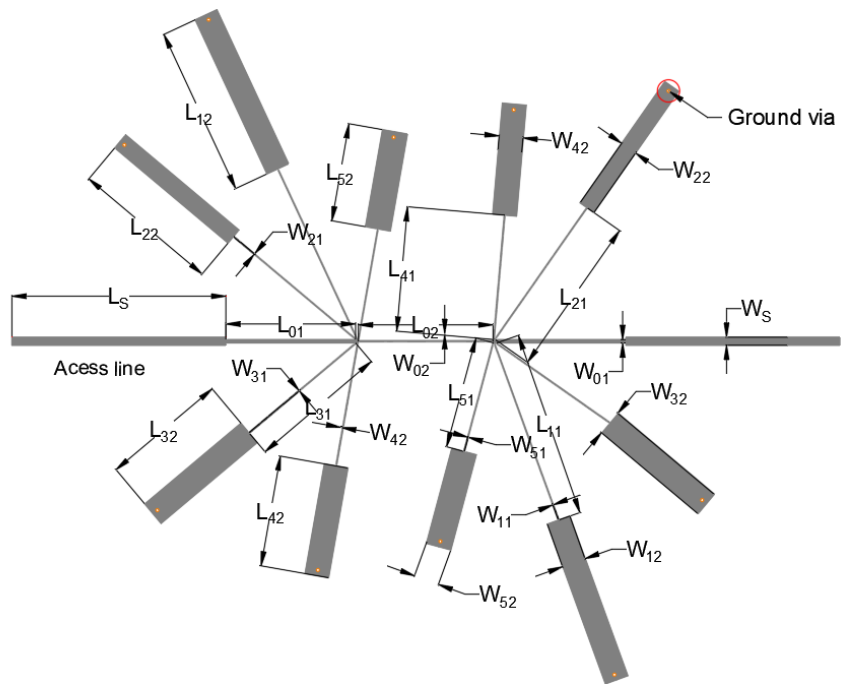

Fig. 5. Layout of the fabricated sext-band filter.

Fig.6 shows the simulated and measured $S$ parameters of the sext-band BPF. A good correlation is obtained by EM simulation and measurement except in terms of insertion losses. Nevertheless, the important measured losses (between 3.3 and $5.5 \mathrm{~dB}$ according to the band) are mainly due to the internal low-cost laser etching realization process which alters the substrate characteristics. The adjacent band-to-band isolation are above $-36.1 \mathrm{~dB},-41.1 \mathrm{~dB},-38.4 \mathrm{~dB},-41.7 \mathrm{~dB}$ and $-39.2 \mathrm{~dB}$ respectively which shows we can achieve sharp and deep rejections between the adjacent pass-bands.

\section{CONCLUSION}

In this paper, a non-coupled sext-band BPF with a star-shape Multi-Shorted-Stub Resonator has been presented. The design procedure is simple and fast and high band-to-band isolation can be easily obtained. The filter had been implemented in microstrip technology to validate the proposed theory. Good agreements have been achieved between simulation and measurements. The proposed Multi-Shorted-Stub Resonator can

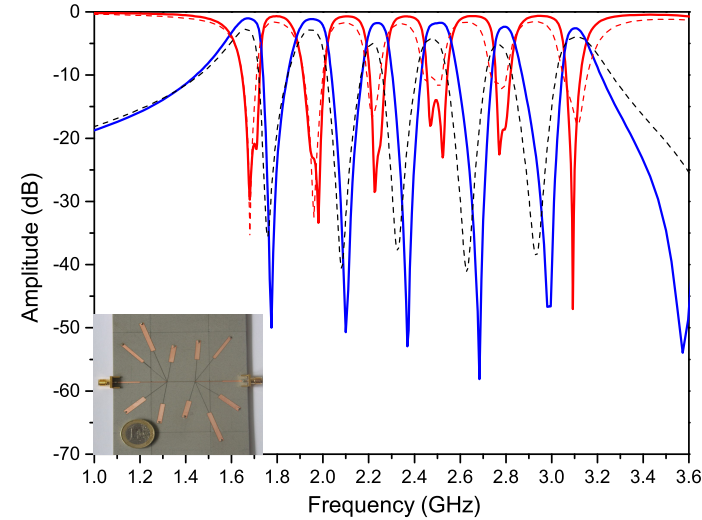

Fig. 6. Simulation (solid lines) and measurements (dashed lines) of the proposed sext-band BPF $-S_{11}$ in red and $S_{21}$ in blue; The photograph of the fabricated sext-band filter.

be used as a building block of high-performance multi-band band-pass filters.

\section{REFERENCES}

[1] K.-W. Hsu, J.-H. Lin, and W.-H. Tu, "Compact sext-band bandpass filter with sharp rejection response," IEEE Microw. Wireless Compon. Lett., vol. 24, no. 9, pp. 593-595, Sep. 2014.

[2] W.-H. Tu and K.-W. Hsu, "Design of sext-band bandpass filter and sextaplexer using semilumped resonators for system in a package," IEEE Trans. Compon., Packag., Manuf. Technol., vol. 5, no. 2, pp. 265-273, Feb. 2015.

[3] J. Ai, Y. H. Zhang, K. D. Xu, Y. Guo, W. T. Joines, and Q. H. Liu, "Compact sext-band bandpass filter based on single multimode resonator with high band-to-band isolations," Electron. Lett., vol. 52, no. 9, pp. 729-731, Apr. 2016

[4] X. K. Li, Y. H. Zhang, Y. Z. Tang, J. Z. Xu, J. Zhang and F. Yong, "Sext-band bandpass filter with compactness based on cascading stage of SIRs," Micro. Opti. Technol. Lett., Vol. 60, no. 2, pp. 306-310, Apr. 2016.

[5] J. Ai, Y. Zhang, K. Da Xu, D. Li, and Y. Fan, " Miniaturized Quint-Band Bandpass Filter Based on Multi-Mode Resonator and $\lambda / 4$ Resonators With Mixed Electric and Magnetic Coupling," IEEE Microw. Wireless. Compon. Lett., Vol. 26, no. 5, pp. 343-345, May. 2016.

[6] C.-F. Chen, S.-F. Chang, and B.-H. Tseng, "Design of compact microstrip sept-band bandpass filter with flexible passband allocation," IEEE Microw. Wireless Compon. Lett. , vol. 26, no. 5, pp. 346-348, May. 2016.

[7] Q. Yang, Y.-C. Jiao, and Z. Zhang, "Compact multiband bandpass filter using low-pass filter combined with open stub-loaded shorted stub," IEEE Trans. Microw. Theory Techn., vol. 66, no. 4, pp. 1926-1938, Apr. 2018.

[8] T. Firmansyah, S. Praptodiyono, A. S. Pramudyo, C. Chairunissa, and M. Alaydrus, "Hepta-band bandpass filter based on folded crossloaded stepped impedance resonator," Electron. Lett., vol. 53, no. 16, pp. 1119-1121, Aug. 2017. 